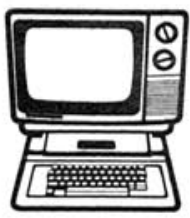

\title{
ARC-ED Curriculum: The Application of Video Game Formats to Educational Software
}

\author{
JERRY D. CHAFFIN \\ BILL MAXWELL \\ BARBARA THOMPSON
}

\begin{abstract}
This article explores the applicability of video arcade game formats to educational microcomputer software. Four variables are discussed as being potentially important to the motivational appeal of video arcade games and several established educational practices are examined in relation to the motivational features of arcade games. Also, guidelines for educational curriculum based on arcade game formats are proposed and the term Arc-Ed Curriculum is offered to describe such software. The content for this article is based on established learning theory and the authors' experience in the development and field testing of six math games based on video game formats.
\end{abstract}

Among the many contributions of advanced computer technology is a fresh social phenomenon-the video arcade game. The motivational appeal of such arcade games as Space Invaders, Asteroids, and Pac Man can be documented by the revenue they return to owners of arcade centers. The popularity of these and other video games has even earned a cover on Time magazine (Games, 1982). Already a fivebillion-dollar-a-year business, video games are likely to increase in popularity as more sophisticated technology is introduced and as arcade entrepreneurs promote their wares. Atari sponsored a championship “Asteroids" playoff last summer and recently a Kansas City radio station encouraged its listeners to compete in the "Pac Man Superbowl." Video games appear to represent exciting entertainment for players of all ages; however, some view the dedicated persistence and involvement with the video games as a potentially dangerous addiction.

In Irvington, New York, citizens were unsuccessful in getting the town's trustees to prohibit children under the age of 17 from playing the video game machines, but the village trustees did agree to levy a heavy license fee for each machine and to limit each place of business to three machines (El News: Anti-Video Game, 1982). In several other communities, citizen's groups have lobbied to make video ma-

Exceptional Children, Volume 49, Number 2. Copyright ${ }^{\circ} 1982$ The Council for Exceptional Children. The substantive content of this article was presented at Harvard Educational Graphics Week, Cambridge, Massachusetts, July 28, 1982. 
chines off limits to minors, especially during school hours, claiming that the video games were contributing to school absenteeism (Games, 1982).

Though there may be some justification for the movement against video arcade games, efforts to limit access to the games will probably serve only to make them more attractive. A more productive approach might be to identify the variables associated with the motivational aspects of the games and to apply these results to learning situations that require high levels of motivation. Some interest has already been shown in this idea. For example, Malone (1981) conducted a series of research studies, with children and adults, related to the motivational aspects of several games available for microcomputers. Malone's interpretation of his results led him to classify the motivational aspects of the games under three major categories: challenge, fantasy, and curiosity. It should be emphasized that Malone's research was based on his subjects' opinions, preferences, and performances on microcomputer games-not video arcade games. Thus, Malone's results and conclusions need to be tempered by the fact that the best of the games used in his research were probably not as powerful, from a motivational point of view, as even the average video game. Even so, Malone must be credited with taking an important early step in this area of research.

More recently, Frederiksen, Warren, Gillote, and Weaver (1982) have described three experimental computer games designed to improve reading skills which incorporate motivational features of video arcade games. The motivational features they cite as important and as being potentially exportable to educational computer instruction are: clear-cut goals, fast pace, immediate feedback, and variable levels of challenge. The purpose of the Frederiksen, et al., article was to describe three applications of their work, and they did not elaborate on how they identified the motivational variables they incorporated into the games.

Between August 1980 and December 1981, the authors conceptualized and developed six educational games based on video game formats and dealing with basic arithmetic facts. The games are now marketed commercially by DLM, Inc. under the trade name of Arcademic Skillbuilders. The term Arcademic is based on the fact that the games represent software which relies substantially on the features of video games to present educationally relevant con- tent. The games all feature high resolution graphics and allow response rates ranging from about 30 to 60 per minute. The teacher may control both the speed of the game and the difficulty level of the problems to be displayed on the screen.

The Arcademic games were designed after systematically observing and interviewing video game players, after hours of personal experience with video games, and by drawing on our professional experiences in education, particularly the education of exceptional children. The remainder of this discussion will address the major considerations and beliefs of the authors as they pertain to the development and use of educational software based on video arcade games. First, the four features of video arcade games which were perceived as the key variables to the high motivational appeal of these games will be identified and defined. Next, several educational premises related to critical processes and procedures related to instructional strategies incorporated into the games will be examined. Finally, the characteristics of these games and implications for future education software will be delineated.

\section{MOTIVATIONAL FEATURES OF VIDEO ARCADE GAMES}

Consideration was given primarily to four motivational features of video arcade games in the development of the Arcademic Skillbuilders. Specifically, these features are feedback, improvement, high response rates, and unlimited ceilings on performance.

\section{Feedback}

Feedback is a primary element of the video game. The player knows instantly whether an individual response was too late, too early, correct, or incorrect. Both visual and auditory feedback are usually provided. Players are provided feedback on the effect of their responses by a constantly updated score on the screen. The player is not provided with reasons that responses were right or wrong. Instead, correction and improvement usually occur as a result of a deductive process. As the player masters the game, the consequences which contribute to or detract from performance are learned. The feedback component is probably the most important feature of the arcade game. 


\section{Improvement}

Change in performance is another key element of the successful video game. Typically, arcade players do poorly on the first few games they play. Rather than perceiving poor initial performance as failure, the players appear to view it as a challenge to improve their scores. Improvement seems to result from two general factors: familiarity and strategy. Familiarity includes understanding the nature or content of the game, the game's sequence or consistent patterns of action, and the consequences associated with the various types of responses. As familiarity grows, the players begin to anticipate events that are likely to occur, develop strategies for these events, and thus improve the accuracy of their performance. The extent to which a player can identify and implement correct strategies is a major determining factor in how well the player scores (Lowe, 1982). Experienced players attain much higher scores than the beginner, but the opportunity to improve performance is always available to both.

\section{High Response Rates}

A third feature of importance is the fast pace of the video games. During the span of a game several hundred responses are not only possible, but are required for good performance. Overt responses (button pressing, handle pulls, etc.) from 30 to more than 100 per minute are not uncommon. Covert responses (decisions) probably occur at the rate of several hundred per minute with the veteran arcade player. Such high rates of response allow for little else-that is, the individual has no time for interfering or distracting thoughts without serious penalty. The task has the player's undivided attention.

\section{Unlimited Ceiling on Performance}

A final variable that seems to be important to the motivational value of the video games is their successive increases in the difficulty level. The fact is that the computer game never losesthe player does! A player may earn "extra time" or other bonuses that prolong the game, but in the end, the computer wins! The increasing level of difficulty is sometimes quite subtle. That is, the player is under the impression that if performance can be improved to a certain point the game will be mastered. Unfortunately, the creators of the game are almost al- ways one step ahead. Just as a player accomplishes one goal, another more difficult situation is introduced. For example, there are more spaceships to be destroyed, they fly faster, return fire with more lasers, or as is usually the case, all of the above. These seemingly negative conditions should, on the surface, result in frustration, discouragement, and disillusionment with the task. However, this is not true with the video games. The unlimited ceiling allows players to continue to improve their skills as their coordination and response times increase and as they employ more effective strategies.

\section{Other Features}

The use of graphics, sound, and color may also be variables which influence the motivational value of video games. However, our observations result in the speculation that these factors are of less importance than the aformentioned features. This is not to say that high quality and relevant graphics, sound, and color do not enhance the overall effect of the video game, but rather that these features, either alone or in combination, are not as powerful as feedback, unlimited ceilings, improvement, and high response requirements.

\section{ARC-ED COURSEWARE FOR EDUCATION}

The same technology available to the arcade game builder is available to educators. Thus, it is not inconceivable that many (though not all) school learning tasks could be presented through the arcade format-or at least include features of arcade games as a means for motivating students to master educational content. The term ARC-ED is offered here to describe educational courseware which relies substantially on the features of video games to present educationally relevant content. ARC-ED courseware would be substantially different than traditional computer-assisted instruction (CAI) materials and different from most games currently available for microcomputers.

Through ARC-ED courseware, certain aspects of classroom instruction can be made as effective in creating persistence and involvement in performance as video games. Such an approach poses an interesting challenge to educational practitioners and researchers. In fact, the adaptation of the arcade format to educational content may require educators, and in 
particular, special educators, to reexamine some basic premises about education and educational processes and procedures. Interestingly, most of these premises have already been considered by Dr. Ogden Lindsley of the University of Kansas and have been implemented by those who use his measurement system of Precision Teaching.

\section{REEXAMINING EDUCATIONAL PREMISES}

One premise in education stresses the importance of success in the learning process. Success has come to mean "correct responses;" teachers seek to place children in curricula where correct responses will be maximized. Special educators have placed considerable emphasis on this premise because of the histories of failure and slower acquisition rate of many exceptional children. The ideal ratio of corrects and errors is often viewed as 90 to $95 \%$. The intent, of course, is to prevent the child from being discouraged as a result of low performance. Often, however, the pupil is placed in curricular sequences that offer little challenge and therefore becomes bored with the task and eventually bored with school.

ARC-ED curriculum should also feature success, but success would be reflected by the amount of improvement and not by correct performance. Therefore, high error rates would be important to the early stages of learning in order to maximize improvement. The less a pupil knows when entering a learning sequence, the more opportunities there are for learning. The benefits of allowing a student to enter a learning sequence with a high error rate has particular relevance to special educators. As opportunities for adaptive living in normalized settings increase for handicapped individuals, the importance of teaching the handicapped student to tolerate entry situations with high error rates and to value improvement also increases.

An additional premise in education which is closely related to the importance of success is the concept that mastery means near $100 \%$ accuracy. As already pointed out, 90 to $95 \%$ accuracy is generally viewed as the ideal ratio of corrects and errors. The fallacy of this assumption is apparent, particularly in the performance of exceptional children, from the large numbers of students who seem to "forget" what they have learned, and need to have individualized education program (IEP) objectives repeated from semester to semester. In addition, the recent emphasis on competency-based testing has focused attention on the large number of students in both regular and special education who never attain the basic tools of reading and computation needed for more complex conceptual performance (Carnegie Council of Policy Studies in Higher Education, 1979).

It is probable that what is lacking in the traditional concept of mastery is the recognition that speed or frequency of performance is as essential as the accuracy of the performance (White \& Haring, 1976; Haughton, 1972). Ignoring the speed at which a student can execute accurate response may result in several consequences. First, students are frequently advanced to the next level too quickly on the basis of performances which are accurate, but slow and tedious. Hence, the degree of mastery necessary to ensure that the student can perform with ease and confidence, retain the skill, and use it to build more complex skills is never achieved. Second, a student who can respond at a higher speed than another has many more opportunities to experience and practice a skill than one who is performing at a lower speed. Consider the difference in performance opportunities between a student who is able to compute basic math facts at the speed of 50 per minute and one who can compute these same facts at the speed of 10 per minute. This difference becomes particularly significant if one considers the number of days, weeks, and years that pupils spend in school.

The ARC-ED approach therefore should maximize true mastery by encouraging proficient performance which is both accurate and of an adequately high frequency. The features of high response rates and no ceiling on performance found in video games both contribute to achieving this aim and should be an integral part of the ARC-ED curriculum.

A third premise in education is the importance of meeting the learner's individual needs. It is a common practice in schools today and in particular in special education classrooms, to emphasize both the formal and informal diagnostic process so that pupils will be taught what they "need" to know. In some cases, the time spent on this process is at the expense of instructional time. For example, a teacher might be aware that a child needs to work on basic arithmetic facts and/or basic sight words. First, a careful analysis of which facts or words a pupil knows and doesn't know would be completed. Next, the teacher would likely focus on 
"processes" which might account for the pupil's learning problems in order to develop programs that teach to the child's strengths or weaknesses or both. Generally, the teacher continues the diagnosis by probing performance on a weekly or even daily basis to remain alert to the pupil's progress and specific problems.

It is assumed among educators that this procedure results in the most efficient use of pupil and teacher time to produce maximum gain. The ARC-ED approach doesn't disregard a pupil's obvious needs, such as "math facts," "sight words," or "word attack skills," nor does it take issue with documentation of performance and data-based instruction. The ARC-ED approach, however, deemphasizes the importance of "error" and "process" analysis as an important variable for successful instruction, even the instruction of exceptional children.

The primary characteristic of ARC-ED courseware is that it is designed to take advantage of students' interests (wants) and to motivate them to learn what they need. Therefore, the students' "wants" are placed well ahead of their specific "needs." The rationale for emphasizing "wants" is that it probably doesn't matter so much to children that they need to learn something -if they don't want to learn it they can in all probability find ways of avoiding it. Thus, creating materials that make pupils want to learn is a basic part of the ARCED approach; meeting specific needs plays a secondary, if not minor, role. This emphasis doesn't mean that we should teach children things they don't need, or not give attention to what they need-it means that once the need is apparent, creating a "want" is the important consideration for optimal learning.

A fourth premise in education stresses the aovidance of high pressure situations which demand structured, rapid and disciplined responding. Special educators tend to want to reduce pressure, to give pupils time to assimilate material, and to provide a calm, pleasant learning environment characterized mainly by a "quiet" classroom. On the surface such a posture has merit. However, the "say it fast" technique introduced by Bereiter and Englemann (1968) in the drill provided by their basic language, reading, and math materials provides evidence which negates this assumption. The rapid, but controlled responses required for this program create feelings of excitement and high levels of involvement which result in a high rate of learning.
Too frequently, traditional methods of drill and practice are tedious, slow, and involve little strategy. To be successful in the ARC-ED approach, a student would need to employ strategy under exciting circumstances which require rapid and repeated responding, while being provided with immediate feedback as to the effectiveness of the responses.

In summary, the ARC-ED approach would represent a reconsideration of several standard educational practices. The incorporation of reinforcement properties which contribute to the motivational features of video games-improvement, high response rate, feedback, and no ceiling on performance-would clearly reflect these differences and may have particular relevance to the education of exceptional children.

\section{CHARACTERISTICS OF THE ARC-ED CURRICULUM}

Based on the previous discussion of the features of video games, and the reexamination of some basic educational premises, it is possible to provide an initial list of characteristics of ARC-ED curriculum materials and some of the tentative educational strategies that would be practiced by Arcademicians (those who believe in and apply the ARC-ED curriculum).

1. ARC-ED courseware should be fast-paced, requiring high response rates. Response rates are relative to the player. What is comfortably fast for a beginner may be tediously slow for a more experienced performer. Thus, program control options should accommodate a wide level of performance possibilities.

2. ARC-ED courseware should provide immediate feedback. The research on "feedback" suggests that courseware developers will have a variety of options for informing pupils of the accuracy of their responses. Feedback may range from simple information of "right" or "wrong," to supplying correct answers when incorrect responses are made, to much more "complex forms reminiscent of instructional tactics"' (Smith, 1981, p. 77).

3. ARC-ED courseware would have an almost unlimited ceiling. Game conditions should be such that as players become more proficient they can continue to increase their scores well beyond traditional levels of mas- 
tery. ARC-ED courseware would penalize the student for slow or incorrect responses by ending the game. The pupil would be rewarded for quick and correct responses by higher scores and/or extended playing time.

4. Arcademicians believe that errors can be viewed as opportunities to improve rather than indicators of failure. Consequently, they start children where they "aren't" rather than where they "are." The focus is on improvement, not correct performance, and strategies for improvement are emphasized.

5. Arcademicians believe that needed repetitions of dull material can be fun and stimulating. They, in fact, consider themselves to be "want makers" rather than "need meeters." They provide educational courseware that utilizes reinforcement properties which are so "motivational" that children want to perform and consequently learn.

6. Arcademicians believe that the ceiling placed on performance by attention only to accuracy is insufficient. They value proficient performance which recognizes that mastery is based on both accuracy and speed. Concern is directed to maximizing the odds that a student will be able to perform with ease and confidence, retain the skill, and utilize it to build more complex performance.

7. Arcademicians believe that students and teachers who receive and utilize feedback are better able to implement performance and instructional strategies which facilitate improvement. It is therefore likely that the feedback provided by the ARC-ED courseware would be documented, analyzed, and utilized as a basis for making decisions related to instructional strategies.

In conclusion, the authors have presented an idea for one of the many educational applications of the microcomputer. Specifically, suggestions have been directed toward utilizing the features of video-arcade games as a basis for developing courseware which presents educationally relevant content. The authors consider this to be a viable alternative to many of the CAI programs currently on the market.

\section{REFERENCES}

Bereiter, C., \& Englemann, S. Teaching disadvantaged children in the preschool. Englewood Cliffs, NJ: Prentice Hall, 1968.

Carnegie Council of Policy Studies in Higher Education. Giving youth a better chance: Options for education, work, and service. San Francisco: Jossey-Bass, 1979.

Chaffin, J. D., \& Ruggles, M. E. Field test results of microcomputer software based on video game formats. National Educational Computing Conference, Kansas City MO, June 29, 1982.

El news: Anti-video game movement gathering momentum. Electronic Learning, 1982, 1(3), 12-14.

Frederiksen, J., Warren, B., Gillote, H., \& Weaver, P. The name of the game is literacy. Classroom Computer News, May/June, 1982, pp. 23-27.

Games that play people. Time, January, 1982, pp. 50-58.

Haughton, E. Aims-growing and sharing. In J. B. Jordan \& L. S. Robbins (Eds.), Let's try doing something else kind of thing. Arlington VA: The Council for Exceptional Children, 1972.

Lowe, Walter Jr. How to survive in the video game jungle. Playboy, March 1982, pp. 167-70, 228, 232-40.

Malone, T. W. What makes computer games fun? Byte, December 1981, pp. 258-277.

Smith, D. D. Teaching the learning disabled. Englewood Cliffs, NJ: Prentice-Hall, 1981.

White, O. R., \& Haring, N. G. Exceptional teachingA multimedia training package. Columbus $\mathrm{OH}$ : Charles E. Merrill, 1976.

\section{TETRA scan II}

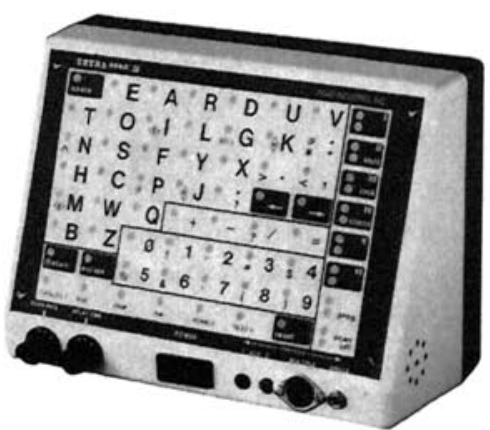

Single switch access to the APPLE ][* Computer

- Allows your physically disabled students to enjoy the same Computer Aided Instruction that other students do!

- To find out how, call or write:

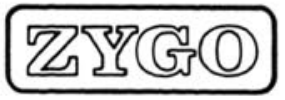

ZYGO INDUSTRIES, INC. P.O. Box 1008 Portland, OR $97207-1008$ (503) 297.1724

•TM Apple Computer, Inc. 